\title{
Influence of the oil industry on anthropogenic changes in natural landscapes
}

\author{
Roza Akhmiyeva* \\ Chechen State University named after A.A.Kadyrov, 364024, st. Sheripova, 32, Grozny, Russia
}

\begin{abstract}
Like most industrial enterprises, the oil industry can have an impact on the environment at several stages. The greatest impact is exerted by the release of waste into the environment in unnatural concentrations. In almost all cases, adverse impacts can be minimized or eliminated by implementing an appropriate waste management plan. In the past few years, the oil industry has been paying more attention to minimizing the environmental impact of its activities at all major stages of the life cycle of a hydrocarbon reservoir: from appraisal to field development, from production and production to decommissioning. As a consequence, the oil industry faces significant technical challenges, with great interest and anticipation in emerging technologies such as nanotechnology and alternative solutions such as underground $\mathrm{CO} 2$ storage.
\end{abstract}

\section{Introduction}

Oil and its production have become an integral part of our society. After all, its production has been conducted since 1857 , and the beginning of this industry was laid in Russia, by the great Vasily Kokorev in the small village of Bibi - Eibet, not far from Baku. In the same Baku, a kerosene plant first appeared in 1863 [1]. Its appearance marked a new era - the era of hydrocarbons. However, in those days, they could not think with what force this type of industry would grow. Indeed, now oil fields occupy hundreds, if not thousands, of square kilometers of area, literally, in all natural zones of our planet. And no one at that time had any idea what the load would be on the natural complexes. Most of the easily recoverable oil and gas reserves have already been developed. As the number of reservoirs found in extremely challenging environments is constantly increasing, traditional operations or technologies may become less efficient. In addition, growing environmental concerns have generated new understandings that are propelling today's societies, industry and governments to safer preserving our planet. As a consequence, the oil industry faces significant technical challenges that are driving it towards more efficient, less costly and environmentally friendly solutions. Increasing hopes are pinned on emerging technologies such as nanotechnology, which have already made breakthroughs in innovative and environmentally friendly technologies in many other areas of industry [2].

\footnotetext{
*Corresponding author: roza2900@mail.ru
} 
Most of the easily recoverable oil and gas reserves have already been developed. As the number of reservoirs found in extremely challenging environments is constantly increasing, traditional operations or technologies may become less efficient. In addition, growing environmental concerns have spawned new understandings that are propelling today's societies, industries and governments to more reliably preserve our planet. As a consequence, the oil industry faces significant technical challenges that are driving it towards more efficient, less costly and environmentally friendly solutions. Increasing hopes are pinned on emerging technologies such as nanotechnology, which have already made breakthroughs in innovative and environmentally friendly technologies in many other areas of industry [3].

The greatest impact on the environment from oil activities arises from the release of waste into the environment in concentrations that do not occur naturally, which negatively affects the quality of soil, air and water. In almost all cases, adverse impacts can be minimized or eliminated by implementing an appropriate waste management plan that takes into account all stages of the hydrocarbon reservoir life cycle prior to decommissioning. In fact, decommissioning planning is an integral part of the overall management process and should be considered early in development during the design phase for both onshore and offshore operations.

\section{Research methodology}

Drilling begins with the appraisal phase and covers the entire life of the reservoir: appraisal wells are designed to check for hydrocarbons and then to assess the size and nature of the reservoir; production or injection wells allow the reservoir to be developed and ultimately sustained by gas / liquid injection. The location of the well site depends not only on the characteristics of the underlying geological formations, but also on the surface constraints [4]. Generally, it is possible to balance environmental criteria with logistical constraints without compromising drilling efficiency. However, most of the easily recoverable oil and gas reserves have already been developed, and new discoveries will increasingly depend on protected area issues and extreme environmental conditions, which, as a result, will affect drilling logistics.

Partly for logistical reasons, mud management and discharge assessment are key issues while drilling. Mud is a mixed clay mineral suspension with thixotropic properties; they are usually oil (OBM) or freshwater (WBM) based. During drilling operations, the fluid circulates in the annulus of the wellbore to maintain the stability of the wellbore and remove drill cuttings (ie, a mixture of formation sand particles, residual drilling mud) from the wellbore [5]. At the surface, drilling solids are removed and the mud is partly recirculated and partly replaced with fresh material. As a result, large quantities of complex mixtures of oil, water and particulate matter are generated that must be disposed of for environmentally sound disposal.

There are many ways to study how different driving forces are contributing to climate change. In principle, observations of the response of climate to one factor can directly show the effect of that factor, or climate models can be used to study the impact of any single factor. In practice, however, it is usually difficult to find measurements that are affected by only one cause, and modeling the response to each individual factor of interest is computationally impermissible. Therefore, to assess the impact on climate of individual factors, various indicators are used, intermediate between cause and effect, with application in both science and policy. Radiation Exposure (RF) is one of the most widely used metrics, with most other metrics based on RF. In this chapter, we discuss RF from natural 
and anthropogenic components during the industrial period, presenting values for 2011 compared to 1750 , unless otherwise indicated, and projected values up to 2100 [6].

\section{Results and Discussions}

In the early stages of conventional reservoir operation, subsurface pressures force the free flow of fluid to the surface. This phenomenon is known as primary production, that is, production from the internal energy of the system. As the system is operating, productivity is approaching the limit of profitable operation due to the progressive loss of energy in the system: further operation of the reservoir may require the use of enhanced oil recovery (IOR) and enhanced oil recovery (EOR) techniques. IOR techniques involve immiscible injection of gas or water to achieve higher recovery rates and prevent excessive reservoir pressure and flow rate drops. EOR approaches are commonly used in heavy oil reservoirs and can be based on thermal processes, miscible gas injection techniques, or chemical processes (Novelli et al., 2005). These additional production methods are usually applied at the end of the life of conventional reservoirs and can improve the final oil recovery. Because heavy oil is a fluid with low dissolved gas content and high viscosity, these unconventional reservoirs typically require early gas, water or steam injection. Environmental impacts associated with primary hydrocarbon production and additional hydrocarbon production operations can potentially affect air and water quality and must be carefully assessed and minimized through appropriate environmental risk management. During the development phase of an oil field, water and gas are often produced and must be disposed of for obvious environmental reasons. Since the goal of production is oil, stripped gas that cannot be used for profit is usually burned, causing unwanted emissions to the atmosphere, including: $\mathrm{CO}, \mathrm{CO} 2, \mathrm{SO} 2, \mathrm{H} 2 \mathrm{~S}, \mathrm{NOx}$, and particulate matter (PM2.5 and PM10) ... The air quality problem becomes even more important for steam thermal enhanced oil recovery technologies used for the production of heavy oil, superheavy oil and bitumen due to toxic emissions associated with steam generators [7-8].

Determining the optimal reservoir exploitation strategy requires proper reservoir characterization, that is, the assessment of some important rock properties, such as porosity, fluid saturation, permeability, heterogeneity, porosity and fluid saturation, is mainly obtained through the so-called log interpretation process. Well logs are measurements of physical parameters such as natural radioactivity, electrical resistivity, and density. Permeability is obtained by interpreting well test results. Well testing has been widely used in the petroleum industry for several decades to evaluate reservoir characteristics such as initial pressure, fluid type and effective permeability, as well as to identify barriers or reservoir boundaries within the reservoir volume investigated during testing. Conventional well testing methods typically involve producing fluids from the surface. In exploration and often in assessment scenarios, onshore storage facilities for reservoir fluids are not available and hence the fluid is flushed or flared. The consequence is the release of significant amounts of unburned hydrocarbons, carbon monoxide and nitrogen oxides, which in turn cause acid rain, smog, ground-level ozone and greenhouse gases in the upper atmosphere. Unconventional well test methods have been proposed to overcome blowout problems. Among the various technologies adopted, several may be potentially hazardous to the environment. 


\section{Conclusions}

Drilling technology is moving towards more efficient, less expensive and cleaner solutions. Directional drilling techniques allow multiple directional wells drilled from the same site to reach spatially distant hydrocarbon formations. Multilateral drilling is another step forward in horizontal or directional drilling by drilling multiple directional wells from a single wellbore. These technologies, in turn, can significantly reduce the impact on the surface associated with drilling operations and allow production from formations that would otherwise be inaccessible with conventional vertical drilling due to environmental constraints [9]. Recent technologies such as thin hole drilling and coiled tubing [10] result in lower costs, less waste, less environmental impact, noise and visual impact, and lower fuel consumption. However, even if this method does not completely replace traditional drilling operations, it can be successfully used in the early stages of production, when identifying newly discovered promising targets, when re-entering existing wells with small bore holes to capture new reserves in mature fields.

As practice shows, geochemical technogenesis is characteristic of all stages of the development of hydrocarbon deposits: drilling of exploration and production wells, development and operation of the field, liquidation of field facilities. The threat of environmental stress to territories and water bodies under anthropogenic impact in the zones of influence of oil and gas technological facilities is aggravated by the moral and physical aging of production assets. The fixed assets of the oil industry already have strong wear and tear and a great age, which leads to an increase in accidents at technological facilities and pipelines. In Russia, in 1998 alone, there were 14195 registered pipeline accidents, of which more than $95 \%$ were due to corrosion. These circumstances, with a high capital intensity and investment inertia of the complex, create a huge threat to the environmental safety of Russia, cause serious concern for government agencies and the public [11].

Therefore, in accordance with the Decree of the President of the Russian Federation No. 230 dated 06/13/96, "On the doctrine of the development of Russian science", priority directions for the development of science and technology were approved, including ecology and rational nature management, in which a certain set of critical technologies was identified, the development and the practical use of which will lead to the improvement of the ecological situation, the development of the economies of the countries, ensuring the growth of the quality of life of the people [12].

Until now, safety analysis in the oil and gas industry is essentially reduced to purely engineering methods of achieving technically justified levels of safety of technological systems and field facilities, and for exceeding the maximum permissible emissions and discharges established for each industrial facility, in the worst case (if it can be proved), a fine is imposed, the size of which does not greatly burden the profitable part of the oil production enterprise. This approach is generally focused on the source of the hazard.

Over the past three decades, research has focused on environmental compliance for the use of oil-based drilling mud, which has fueled the adoption of vegetable oils as substitutes for diesel fuels. The contribution of non-edible oils such as rapeseed oil, jatropa oil, mahua oil, cottonseed oil, sesame oil, soybean oil, palm oil has been widely studied. For example, Xiaoqing and Lihui have developed drilling fluids mainly composed of shale inhibitor agents and fluid loss control agent derived from vegetable gum, non-dusting white asphalt and dry polyalcohol powders. They are free of toxic components and are all biodegradable. Such drilling fluids have been successfully used in the Tarim oil field, in the Taklimakan desert in northwest China and in the Shengli oil field with high requirements for discharge into the sea [13]. Several esters were tested as the outer phase of an inverted emulsion 
obtained from Malaysian biodiesel factories. Esters were field tested for the first time offshore Norway [13]. However, they have shown limited use in inverted drilling fluids due to their physical and chemical properties, such as being highly susceptible to hydrolysis. Water-based mud (WBM) is a viable alternative to OBM, especially in sensitive ecological regions. However, the effective benefits of WBM must be carefully assessed according to the characteristics of the system: in the presence of certain clay minerals (e.g. smectite), they can cause time-dependent wellbore instability phenomena such as wall swelling followed by formation collapse and pipe wrap. which can be so serious that it will force you to abandon the wellbore [15]. Disposing of waste drilling mud and cuttings from well drilling is critical to reducing environmental impact. In onshore activities, drilling waste is collected in a dug sump, which is backfilled upon completion of drilling operations and the landscape is restored. This approach becomes more expensive and logistically challenging as the length and number of wells increases. Slurry treatment and injection of waste generated during drilling into selected subterranean formations by initiating burial fractures were first applied back in 1988. Since then, the industry has accumulated experience and know-how, and therefore slurry and injection have become the preferred technologies for drilling operations in many countries [14].

It must be said that there is a need to assess the forms of changes in the natural environment, as well as the development of a large number of methodological and theoretical problems. Briefly, we can say that the methodological problems include the development of principles for assessing environmental damage, while the theoretical ones include the principles of typing the main violations, as well as their analysis. All this takes a fairly large amount of time and money, but all large companies strive to minimize the impact on the natural environment. And not unimportant is the concept of variability of the natural potential of the normal functioning of the landscape [16]. The essence of this principle is that the same pollutants behave completely differently in different natural environments. Somewhere they become inverted, and somewhere they undergo active changes up to complete destruction. Of course, minimization of technogenic impact is also possible with the evolution and refinement of technical systems, as well as technological discipline, but taking into account the natural potential of the normal functioning of the landscape on the territory, the stability of Geosystems will be more adapted to various see loads. In conclusion, I would like to say that the influence of oil production on the natural environment is of a growing nature, and it is associated with our active consumption. And with this we need to think about our future, because no one knows where the "oil needle" can lead us.

\section{References}

1. V. V. Bardyuk., L. S. Stoyko, On the issue of an integrated assessment of the quality of surface waters (2020)

2. G. A. Bogdanovsky, Chemical Ecology (2018)

3. E. A. Beretta, A. Tiani, G. L. Presti and F. Verga, Injection tests as a reliable alternative to conventional well testing (2018)

4. J. J. Andrea, C. Burns, J. Touza, Renewable Energy as a Luxury? A Qualitative Comparative Analysis of the Role of the Economy in the EU's Renewable Energy Transitions During the 'Double Crisis', Ecological Economics, 142, 81-90 (2020) 
5. J. Yang, F. Zhang, X. Jiang, W. Sun, Strategic Flexibility, Green Management, and Firm Competitiveness in an Emerging Economy, Technological Forecasting and Social Change, 101, 347-356 (2018)

6. H. B. Dulal, R. Dulal, P. K. Yadav, Delivering Green Economy in Asia: The Role of Fiscal Instruments, Futures, 73, 61-77 (2019)

7. J. Mauritzen, Contractors and Scale: An Empirical Analysis of the California Solar Market (2020)

8. J. Meckling, L. Hughes, Protecting Solar: Global Supply Chains and Business Power, New Political Economy, 23(1), 88-104 (2020)

9. S. D. Belyaev, Using water quality targets in water management planning (2020)

10. A. M. Vladimirov, F. A. Imanov, Principles for assessing the ecological flow of rivers (2019)

11. F. Imanov, M. Ya. Asadov, Assessment of water resources and ecological state of the Samur River (2019)

12. A. N. Elizariev, T. B. Fashchevskaya, Assessment of water potential using GIS technologies (2018)

13. V. P. Emelyanova, G. N. Danilova, T. Kh. Kolesnikova, Assessment of the quality of land surface waters by hydrochemical indicators (2020)

14. N. I. Egorova, O. I. Mityakova, Environmental Innovation and Sustainable Development (2020)

15. R. A. Gakaev, I. A. Bayrakov, Geomorphological conditions of landslide formation in the Itum-Kalinskaya depression of the Chechen Republic (2018)

16. A. A. Daukaev, R. Kh. Dadashev, L. S. Gatsaeva, R. A. Gakaev, Landslides and mudflows in the Chechen Republic: synergetic aspects (2019) 